\title{
CEREBELLAR DEGENERATION SECONDARY TO ACUTE LITHIUM CARBONATE INTOXICATION
}

\author{
Ana Claudia Rodrigues de Cerqueira ${ }^{1,3 A}$, Moema Costa dos Reis ${ }^{2 B}$, Fernanda Demôro Novis ${ }^{2 B}$, \\ José Marcelo Ferreira Bezerra ${ }^{1 C}$, Gérson Canedo de Magalhães ${ }^{1 D}$, \\ Márcia Rozenthal ${ }^{4 C}$, Antônio Egídio Nardi ${ }^{3 \mathrm{C}}$
}

In 1949, Cade described the therapeutic effects of lithium in ten patients with chronic and recurrent manic'. Lithium has been the first line drug for the past five decades, since its introduction, in treating bipolar disorder ${ }^{2,3}$. Its therapeutic effects are undeniable; it is efficient in reducing manic and depressive crises in bipolar patients, in addition to producing an anti-suicide effect. Nevertheless, toxic reactions are common and are directly correlated to the serum drug concentration ${ }^{4}$. Acute lithium intoxication may cause several neurological manifestations such as tremor, ataxia, dysarthria, seizures and in the more severe cases encephalopathy and coma. Neuromuscular manifestations include proximal muscle weakness, rhabdomyolysis, a myasthenia gravis-like syndrome and axonal neuropathy ${ }^{5}$. These changes are usually reversible with the drug's reduction or suspension. However, few cases of persistent neurological deficits have been reported ${ }^{5-7}$. In such cases the presence of cerebellar signs are predominant and neuropathological studies have demonstrated a reduction of Purkinje cells in the cerebellar cortex and spongiform changes in the cerebellum's white matter ${ }^{8}$.

We describe the case of a patient with bipolar disorder on lithium carbonate who presented with cerebellar degeneration secondary to acute lithium intoxication.

\section{CASE}

A female patient, 26 years old, nigro, from Rio de Janeiro, started presenting two weeks ago fever, productive cough, vomiting, tremor and changes in gait. She had been diagnosed with bipolar disorder five years ago and was on regular use of $1500 \mathrm{mg} /$ day lithium carbonate. There was no prior history of neurological disease. The patient presented at admission mild fever, tachycardia, dehydration and pulmonary auscultation revealed the presence of bilateral crackling rales. The neurological examination showed a sleepy, disoriented, dysarthric patient with tremors in the extremities, symmetrical deep reflexes and flexor plantar responses. Other than this, the physical examination was normal.

Chest $\mathrm{X}$-rays, $\mathrm{CBC}$ and serum lithium tests were requested which confirmed the bacterial pneumonia diagnosis and acute lithium intoxication. Serum lithium concentration was $1.9 \mathrm{mEq} /$ $\mathrm{L}$, above therapeutic values (0.6-1.2 mEq/L).

The medication was immediately interrupted and treatment for the respiratory infection was initiated with cefriaxone $2 \mathrm{~g} /$ day for 14 days. During the first weeks of treatment there was a clear improvement of the infection and level of consciousness. However, cerebellar signs were prominent and the patient was unable to walk. The patient's neurological status improved in the first six months and she began walking with an unsteady gait. She presented ataxia, dysarthria, dysmetria and discreet hypotonia.

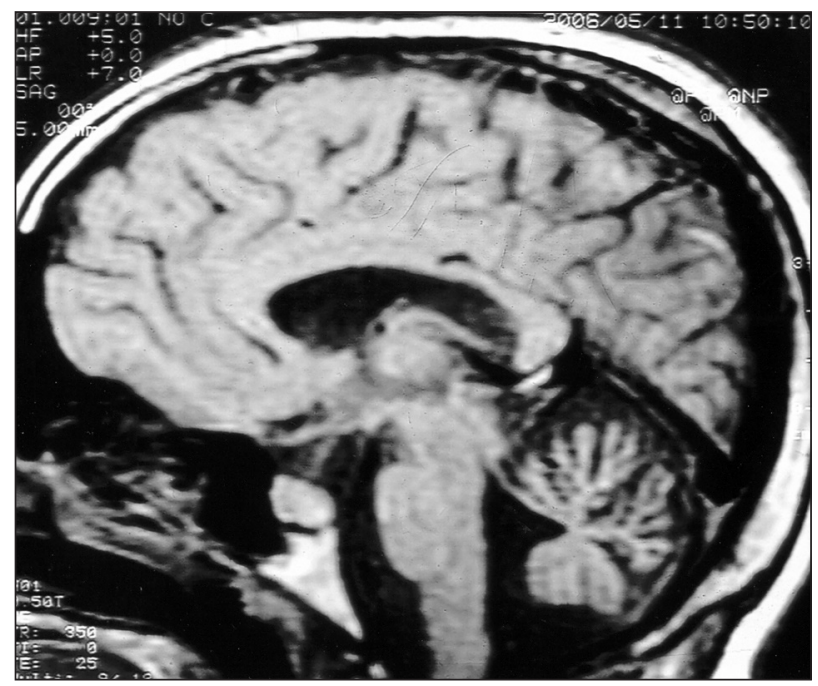

Figure. Brain MRI: sagittal section in T1 without contrast, showing marked cerebellar atrophy in a patient with bipolar disorder and persistent cerebellar signs secondary to lithium intoxication.

\section{DEGENERAÇÃo CEREBELAR SECUNDÁRIA À INTOXICAÇÃo AGUDA POR CARBONATO DE LÍTIO}

Pedro Ernesto University Hospital of the University of the State of Rio de Janeiro (HUPE/UERJ): ${ }^{1}$ Neurology Service at the State University of Rio de Janeiro RJ, Brazil; 'Psychiatry Service at the State University of Rio de Janeiro RJ, Brazil; ${ }^{3}$ Institute of Psychiatry at the Federal University of Rio de Ja-

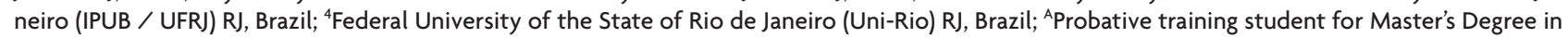
Psychiatry; ${ }^{\mathrm{B}}$ Medical Resident; ${ }^{\mathrm{C}}$ Associate Professor; ${ }^{\mathrm{D}}$ Full Professor.

Received 26 February 2008, received in final form 2 June 2008. Accepted 19 June 2008.

Dra. Ana Claudia Rodrigues de Cerqueira - Rua Trajano de Moraes 42/701 - 24230-380 Niterói RJ - Brasil. E-mail: anacerqueira@globo.com 
After two years a magnetic resonance image (MRI) of the skull was performed and showed significant cerebellar atrophy with the other encephalic structures preserved (Figure).

Cerebellar signs became persistent after a three year follow-up.

Treatment for bipolar disorder was maintained with divalproate $1000 \mathrm{mg} /$ day. The patient authorized the publication of the case upon signature of an informed consent form.

\section{DISCUSSION}

Lithium carbonate is the first line drug in treating bipolar disorder. It is efficient in treating manic and depressive crises in addition to reducing the risk of suicide in bipolar disorder patients ${ }^{2,9}$. However, signs of neurotoxicity such as tremor, dysarthria, ataxia, seizures, encephalopathy and coma can occur as treatment complications ${ }^{6}$. These manifestations are usually related to supratherapeutic levels of the drug and are reversible with drug dose reduction or drug interruption ${ }^{10}$.

Persistent neurological deficits have been reported in some cases of lithium carbonate intoxication ${ }^{5,7}$. In these cases, cerebellar signs such as ataxia, dysarthria, dysmetria and tremor of the extremities are predominant. There are, apparently, several neurotoxicity predisposing factors such as acute infections, hyperthermia, hyponatremia, dehydration, renal failure and drug interactions ${ }^{11}$. A combination of antipsychotic drugs and lithium is common and believed to be safe for treating bipolar disorder, but may cause encephalopathy and permanent cerebellar damage ${ }^{12}$. Antipsychotic drugs, particularly fenotiazines, may increase lithium input to red blood cells thus leading to an increase in erythrocyte lithium concentration and neurotoxicity ${ }^{13}$. An association between pneumonia and cerebellar degeneration has been reported in patients presenting therapeutic lithium concentrations ${ }^{14}$. Experimental trials demonstrated that lithium uptake by the central nervous system is not uniform, it may be high in the brain while remaining at therapeutic levels in the plasma $^{15}$. These data suggest that the presence of serum lithium concentrations above therapeutic levels is not mandatory and that lithium's neurotoxicity mechanism seems to be a multi-factorial one.

A likely association between lithium toxicity and cerebellar degeneration has been suggested by neuropathological studies which have demonstrated a reduction in the number of Purkinje cells with preservation of the "basket" cells of the cerebellar cortex, spongiform changes of the white matter and changes in the dentate nucleus ${ }^{8}$. Experimental studies have shown that the mechanisms that regulate the entrance of calcium into Purkinje cells are also affected by lithium ${ }^{16}$. However, the mechanisms that explain this selectivity are yet unknown and need to be further elucidated.

We reported the case of a patient undergoing treatment for bipolar disorder who presented bacterial pneumonia, acute lithium intoxication, encephalopathy and remained with persistent cerebellar signs. Some factors contributed to the lithium neurotoxicity such as acute infection, hyperthermia and dehydration. However, she was not on any regular drugs that could determine intoxication such as antipsychotic or non-hormonal antiinflammatory drugs. An association between bacterial pneumonia and encephalitis has been described, but in these cases neurological symptoms begin during or after the respiratory infection and the MRI indicates changes in the white matter. The prognosis is good and in most cases patients recover fully ${ }^{17}$. In this report, the neuroimaging test showed marked cerebellar atrophy, thus excluding any vascular, demyelinating or infectious etiology associated to pneumonia. Lithium serum concentration above the therapeutic level and changes in the MRI confirmed the diagnosis of cerebellar degeneration. Treatment with lithium carbonate was reinitiated after neurotoxicity in only a few reported cases in the literature, however, in only one case lithium therapy led to the worsening of cerebellar signs, even in the presence of lithium serum levels within therapeutic levels ${ }^{5}$. In the present case, we chose to treat her with divalproate because it is a good therapeutic choice for the treatment of bipolar disorder. The outcome was favorable in the first six months after neurotoxicity and the patient went back to walking without any support. However, she presented significant cerebellar signs such as dysarthria, gait ataxia and dysmetria. Her condition remained stable during a three year follow-up. In some cases that have been described, improvement of the neurological symptoms occur between the first six to twelve months post neurotoxicity, however a complete reversal of the symptoms after this period is rare ${ }^{7}$.

This case highlights the importance of care that must be taken against lithium neurotoxicity and the potentially disabling effects in patients on continuous use of lithium, particularly in those with bipolar disorder. Many authors have defended the use of psycho-educational measures with the purpose of reducing complications from lithium treatment ${ }^{18}$. On the other hand, the diagnosis of cerebellar degeneration secondary to acute lithium intoxication should always be considered as a differential diagnosis from other pathologies that also present persistent cerebellar syndrome especially in patients with mood disorders. 


\section{REFERENCES}

1. Cade JFI. Lithium salts in the treatment of psychotic excitement. Med J Aust 1949;36:349-352.

2. Canadian Network for Mood and Anxiety Treatment. (2006) Canadian Network for Mood and Anxiety Treatments (CANMAT). Guidelines for the management of patients with bipolar disorder: update. Bipolar Disord 2007;8:721-739.

3. Schou M. Forty years of lithium treatment. Arch Gen Psychiatry 1997;54:9-13.

4. Frazer A, Mendels J,Brunswuck D, et al. Erythrocyte concentrations of lithium ion: clinical correlates and mechanisms of action. Am J Psychiatry $1978 ; 9: 135-139$

5. Niethammer M, Ford B.Permanent Lithium-induced cerebelar toxicity: three cases and review of literature. Mov Disord 2007;22:570-573.

6. Grignon S, Bruguerolle B. Cerebellar lithium toxicity: a review of recent literature and tentative pathophysiology. Therapie 1996;51:101-106.

7. Nagaraja D, Taly AB, Sahu RN, Channabasavanna SM, Narayanan HS Permanent neurological sequelae due to lithium toxicity. Clin Neurol Neurosurg 1987;89:31-34.

8. Scheneider JA, Mirra SS. Neurophathologic correlates of persistent neurologic deficit in lithium intoxication. Ann Neurol 1994;36:928-931.

9. Young AH, Hammond JM. Lithium in mood disorders: increasing evidence base, declining use? Br J Psychiatry 2007;191:474-477.
10. Sheean GL. Lithium neurotoxicity. Clin Exp Neurol 1991;28:112-127.

11. Roy M, Stip E, Black D, Lew V, Langlois R. Cerebellar degeneration following acute lithium intoxication. Rev Neurol 1998;154:546-548.

12. Emilien G, Maloteaux JM. Lithium neurotoxicity at low therapeutic doses: hypotheses for causes and mechanism of action following a retrospective analysis of published case reports. Acta Neurol Belg 1996;96:281-293.

13. Gille M, Ghariani S, Pieret F, et al. Acute encephalomyopathy and persistent cerebellar syndrome after lithium salt and haloperidol poisoning. Rev Neurol 1997;153:268-270.

14. Ozsoy S, Basturk M, Esel E. Cerebellar syndrome in a patient with pneumonia under lithium treatment: case report. Prog Neuro Psychopharmacol Biol Psychiatry 2006;30:1532-1534.

15. Herteaux C, Ripoll C, Ouznadji S, Wissocg JC, Thellier M. Lithium transport in the mouse brain. Brain Res 1991;547:122-128.

16. Dixon JF, Los GV, Hokin LE. Lithium stimulates glutamate release and inositol 1,4,5-triphosphate accumulation via activation of the N-methyl-D-aspartate receptor accumulation in monkey and mouse cerebral cortex slices. Proc Natl Acad Sci U S A 1994;91:8358-8362.

17. Ropper AH, Brown RH. Adam and Victor Principles of neurology $8^{\text {th }}$ Ed. New York. McGraw-Hill, 2005;601-602.

18. Colom F, Vieta E, Sanchez-Moreno J, et al. Stabilizing the stabilizer: group psychoeducation enhances the stability of serum lithium levels. Bipolar Disord 2005;7(Suppl 5):S32-S36. 